\title{
Polarimetric remote sensing of atmospheric particulate pollutants
}

\author{
Zhengqiang $\mathrm{Li}^{1}{ }^{1, *}$, Ying Zhang ${ }^{1}$, Jin Hong ${ }^{2}$ \\ ${ }^{1}$ Institute of Remote Sensing and Digital Earth, CAS, 100101, Beijing, China - lizq@radi.ac.cn \\ ${ }^{2}$ Anhui Institute of Optics and Fine Mechanics, CAS, 230031, Hefei, China
}

KEY WORDS: Polarization, Remote sensing, Atmosphere, Particulate Matters, Pollution

\begin{abstract}
:
Atmospheric particulate pollutants not only reduce atmospheric visibility, change the energy balance of the troposphere, but also affect human and vegetation health. For monitoring the particulate pollutants, we establish and develop a series of inversion algorithms based on polarimetric remote sensing technology which has unique advantages in dealing with atmospheric particulates. A solution is pointed out to estimate the near surface $\mathrm{PM}_{2.5}$ mass concentrations from full remote sensing measurements including polarimetric, active and infrared remote sensing technologies. It is found that the mean relative error of $\mathrm{PM}_{2.5}$ retrieved by full remote sensing measurements is $35.5 \%$ in the case of October $5^{\text {th }} 2013$, improved to a certain degree compared to previous studies. A systematic comparison with the ground-based observations further indicates the effectiveness of the inversion algorithm and reliability of results. A new generation of polarized sensors (DPC and PCF), whose observation can support these algorithms, will be onboard GF series satellites and launched by China in the near future.
\end{abstract}

\section{INTRODUCTION}

Particulate matters (PM) are the major atmospheric pollutants in most of human-living and natural environments. The monitoring of these pollutants that have characteristics of rapid changes in time and huge spatial diversity is a big challenge in environmental management. With the advance of space techniques for environmental monitoring, the satellite becomes a powerful tool to survey atmospheric pollution from orbit for vast regions with quick re-visiting capability.

In recent years, the method of retrieving the aerosol optical depth (AOD) has become more and more mature, and the retrieval algorithms of AOD have been developed based on many satellite platforms. For example, the AOD product that is retrieved by the dense dark vegetation (DDV) method of the Moderate-resolution Imaging Spectroradiometer (MODIS) platform (levy et al., 2007; Kaufman et al., 1997) has been widely used in atmospheric and environmental studies. A mathematical method, empirical orthogonal function (EOFs), is used to retrieve the AOD from the Multi-angle Imaging SpectroRadiometer (MISR). With the launch of polarimetric sensors (the Polarization and Directionality of Earth's Reflectance (POLDER) and Polarization and Anisotropy of Reflectances for Atmospheric Science coupled with Observations from a Lidar (PARASOL) instruments), polarized passive radiometric remote sensing provides a new research dimension in the field of aerosol retrieval (Tanré et al., 2011; Deuzé et al., 2001). Among serval satellite monitoring approaches, the polarimetric remote sensing is one of the promising technique to monitor atmospheric particulate matters, especially small particulates (i.e. $\mathrm{PM}_{2.5}$ ), which have important influence on human health.

Aiming for $\mathrm{PM}_{2.5}$ remote sensing, earlier studies tended to suppose unknown relationships between $\mathrm{AOD}$ and $\mathrm{PM}_{2.5}$ and commonly employed the linear regression to represent their correlation (e.g. Engel-Cox et al., 2004, 2005; Wang \& Christopher, 2003). Further studies thus developed many statistical expressions and model convert to describe the AOD$\mathrm{PM}_{2.5}$ relationship (e.g. Liu et al., 2009; van Donkelaar et al.,
2010). But all of these methods are lack of the capable of providing monitoring of $\mathrm{PM}_{2.5}$ spatial distribution independent of geological location, sample data training and atmospheric chemical model simulation. The physical method of $\mathrm{PM}_{2.5}$ remote sensing (PMRS) model (Zhang et al., 2015) can be a neat solution to these problems.

In this study, we show the near surface $\mathrm{PM}_{2.5}$ estimate using PMRS model based on satellite joint observation. The PMRS model is explained in Section 2. The utility for air quality monitoring in North China is demonstrated by case study using the joint observation of POLDER, CALIOP, MODIS in Section 3. Section 4 focuses on the substitute observations with the Chinese polarimetric sensors in the near future. The conclusions and discussions are given in Section 5.

\section{METHOD}

\subsection{PMRS Model}

The PMRS method (Zhang et al., 2015) aims to utilize remote sensing measurements as many as possible to obtain particulate mass concentration of dry $\mathrm{PM}_{2.5}$ near the ground, which is the different starting-point with other methods. The PMRS model estimates the $\mathrm{PM}_{2.5}$ mass concentration is start from aerosol optical depth(AOD), and the major procedures of the PMRS method include size cutting with fine-mode fraction (FMF) parameter, volume visualization with volume-to-extinction of fine mode $\left(\mathrm{VE}_{\mathrm{f}}\right)$, bottom isolation with planet boundary layer height (PBLH), particle drying with relative humidity $(\mathrm{RH})$ and mass weighting procedures using particle density $(\rho)$. This simplified theoretical model is used to characterize the atmosphere and aerosols with three assumptions: (i) All of particulate matters are uniformly mixed in a homogeneous layer with the layer top at Planetary Boundary Layer Height (PBLH); (ii) Aerosol size and absorption properties are independent with height; (iii) The hygroscopic properties of particles are independent of aerosol size. Based on the above assumptions, the $\mathrm{PM}_{2.5}$ mass concentration can be estimated using the formula (1) 


$$
P M_{2.5}=A O D \frac{F M F \cdot V E_{f}(F M F) \cdot \rho_{f, d r y}}{P B L H \cdot f_{o}(R H)} .
$$

The $\mathrm{VE}_{\mathrm{f}}$ can be calculted by the formula (2) with the FMF between of 0.1 to 1 .

$$
V E_{f}(F M F)=0.2887 F M F^{2}-0.4663 F M F+0.356
$$

\subsection{AOD and FMF retrieved by POLDER}

AOD: The PMRS method requires to be supported by advanced spaceborne sensor. The polarimetric sensor is thought to have a unique advantage in identifying fine particles. An AOD retrieval method, which is a key parameter in the PMRS model, was developed based on the multi-angle intensity data from the Polarization and Anisotropy of Reflectances for Atmospheric Science coupled with Observations from a Lidar (PARASOL) platform using empirical orthogonal functions (EOFs), which can be universally applied to multi-angle observations (Zhang et al., 2017). The function of EOFs in this study is to estimate surface intensity contributions, associated with aerosol lookup tables (LUTs), so that the retrieval of AOD can be implemented.

FMF: The key parameter FMF was further retrieved also by PARASOL data taking the advantage of the coincident multiangle intensity and polarization measurements from a single satellite platform (Zhang et al., 2016). The intensity measurements to retrieve the total AOD based the EOFs function as previously mentioned, and the polarization measurements are applied to retrieving the fine-mode AOD. The FMF is then calculated as the ratio of the retrieved fine-mode AOD to the total AOD. The important processes in our method include the estimation of the surface intensity and polarized reflectance by using two semi-empirical models, and the building of two sets of aerosol retrieval lookup tables for the intensity and polarized measurements via the 6SV radiative transfer code. The whole retrieval process is shown in Figure 1.

\subsection{PBLH retrieved by CALIOP}

The PBLH is estimated using the attenuated backscatter coefficient by the maximum variance technique. This technique relies on the strong aerosols concentration gradient at the top of the PBL, which can be detected by looking for the maximum in the vertical standard deviation of Lidar backscatter (Zhang et al., 2014; Liu et al, 2017). To guarantee the accuracy, we chose the non-cloud data and horizontally average over $17 \mathrm{~km}$ to increase signal noise ratio. We also use depolarization to check data quality.

\section{RESULTS}

\subsection{Satellite monitoring $\mathbf{P M}_{2.5}$ scenarios}

In this study, we put forward a near surface $\mathrm{PM}_{2.5}$ solution using physical PMRS model relying on full remote sensing observation. The model parameters can be obtained from multisensors in A-Train including POLDER (PARASOL), CALIOP (CALIPSO) and MODIS (AQUA). Then, the near surface $\mathrm{PM}_{2.5}$ mass concentration can be estimated along the ground track of CALIPSO (Figure 1).

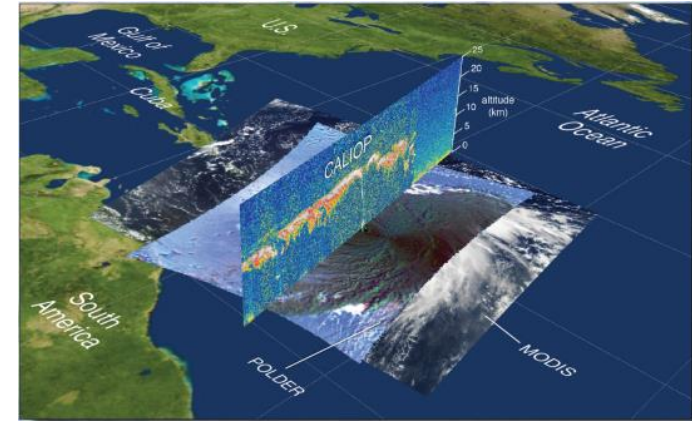

Figure 1. Combing satellite observation to monitor $\mathrm{PM}_{2.5}$ (Figure derived from https://atrain.nasa.gov/stories.php)

\subsection{Case Study}

With the acceleration of China's industrialization, air pollution is becoming more and more serious. Figure 2 shows a heavy haze pollution over the North China on October $5^{\text {th }}, 2013$. This haze event lasted from October $4^{\text {th }}$ to $7^{\text {th }}$, and reached its peak on $5^{\text {th }}$. The average daily $\mathrm{PM}_{2.5}$ concentration can be up to 304 $\mu \mathrm{g} \mathrm{m}^{-3}$ observaed by ground sites on the peak day. Zhang and $\mathrm{Li}$ (2015) have showed the preliminary results that the higher instantaneous value on $5^{\text {th }}$ has been estimated beyond $400 \mu \mathrm{g} \mathrm{m}^{-}$ ${ }^{3}$ by MODIS, but that results use the PBLH and $\mathrm{RH}$ are simulated by mesoscale meteorological model WRF.

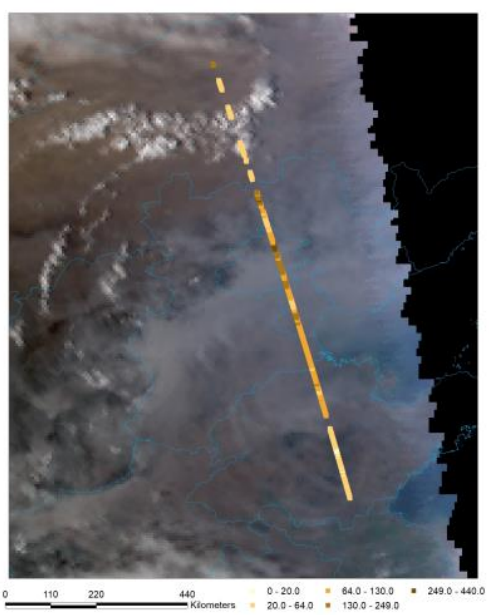

Figure 2. The satellite image overlayed by the $\mathrm{PM}_{2.5}$ mass concentration on October $5^{\text {th }}, 2013$.

In this study, to estimate the near surface $\mathrm{PM}_{2.5}$ mass concentrations from the full remote sensing measurements, the multi-stokes-component, multi-wavelength and active-passive remote sensing observations are applied to retrieving the key parameters of PMRS model. Figure 3 shows the retrievals of AOD, FMF, PBLH and RH distributions. It can be found that the most serious pollution is around the city of Shijiazhuang Hebei province, which shows clearly in the AOD map, but the FMF presents low values. The PBLH is relative stable around $1 \mathrm{~km}$ and the $\mathrm{RH}$ distribution hints the moister over the pollution area than others. 


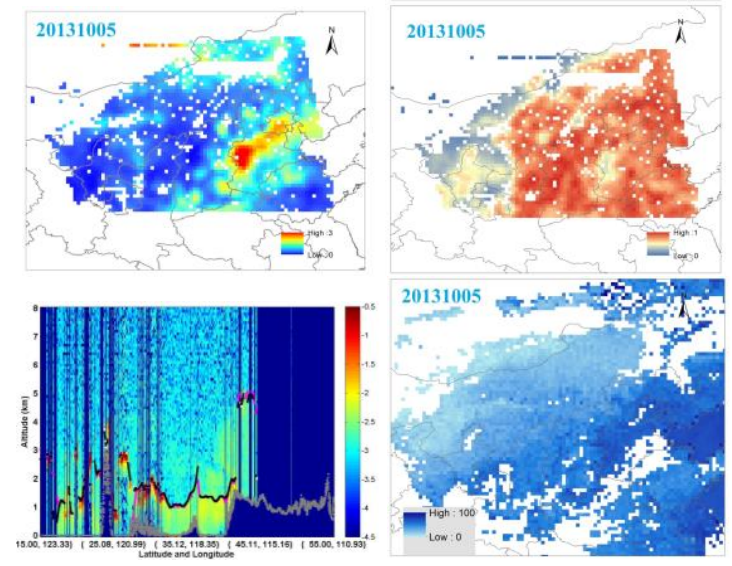

Figure 3. The retrival distributions of AOD, FMF, PBLH and RH on October $5^{\text {th }}, 2013$.

Figure 4 shows a fairly reasonable distribution of $\mathrm{PM}_{2.5}$ mass concentrations along the satellite ground track. The high $\mathrm{PM}_{2.5}$ appears near Beijing, with the peak of $\mathrm{PM}_{2.5}$ mass concentration is up to $275 \mu \mathrm{g} \mathrm{m}^{-3}$ and decreases in Shandong and Inner Mongolia province agreed with that of ground sites. For validation, the $\mathrm{PM}_{2.5}$ observed at ground sites are employed and the satellite estimates averaged over the region of $0.2^{\circ} \times 0.2^{\circ}$. The ground observations are matched with the satellite ground track within a distance no more than $0.15^{\circ}$. The maximum of these matching estimates is $142 \mu \mathrm{g} \mathrm{m}^{-3}$, comparable to the ground observation $\left(124 \mu \mathrm{g} \mathrm{m}^{-3}\right)$ at Beijing site $\left(117.18^{\circ}\right.$, $39.12^{\circ}$ ). The mean relative error from the matching sites is $35.5 \%$, very close to that from a ground-based remote sensing observation experiment (Li et al., 2014).

\subsection{Validations and Comparisons}

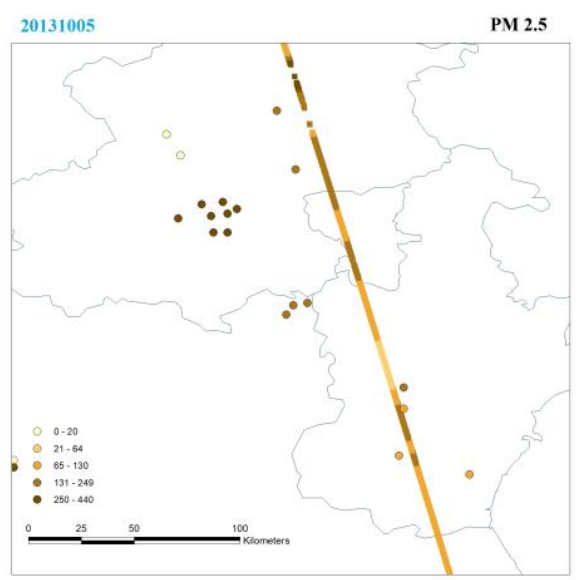

Figure 4. The estimates and ground observations of $\mathrm{PM}_{2.5}$ mass concentrations.

A comparison of the retrieved AODs for the Beijing, Xianghe, Taihu, and Hongkong_PolyU sites from 2011 to 2013 with those from the Aerosol Robotic Network (AERONET) groundbased observations produced high correlation coefficients ( $r$ ) of $0.892,0.915,0.831$, and 0.897 , respectively, while the corresponding root mean square errors (RMSEs) are 0.095, 0.093, 0.099, and 0.076, respectively (Zhang et al., 2017). The FMF retrievals are validated over the entire annual cycle of 2012 at the Beijing, Xianghe and Seoul_SNU sites with those of the Aerosol Robotic Network (AERONET) ground-based observations produce correlation coefficients $\left(\mathrm{R}^{2}\right)$ of 0.838 , 0.818 , and 0.877 , respectively. However, the comparison results are relatively poor $\left(\mathrm{R}^{2}=0.537\right)$ in low-AOD areas, such as the Osaka site, due to the low signal-to-noise ratio of the satellite observations (Zhang et al., 2016). A ground-based remote sensing observation experiment has been carried out in basin area of Jinhua city, Zhejiang province during December 14 - 31, 2013 to validate the PMRS model and analysed the error sources. It is found that relative error of $\mathrm{PM}_{2.5}$ mass concentration estimated from PMRS model is approximated to the model inherent error ( $31 \%$ vs $34 \%$ ) due to the accurate inputs from the ground-based remote sensing ( $\mathrm{Li}$ et al., 2016). Although the case study shows the only one day results, the relative error is close to the model inherent error and better than that computed from MODIS measurements and model simulations (Zhang and $\mathrm{Li}, 2015$ ). It is mean that the accuracy of $\mathrm{PM}_{2.5}$ estimates can be effectively improved by decreasing the uncertainties of model input parameters. At present, the new generation of inversion algorithms have been preliminarily established introduced in section 2, but there is no polarimetric sensor in orbit. Therefore, launching new sensors is an urgent problem to be solved in the near future.

\section{CHINESE POLARIMETRIC SENSORS}

\subsection{DPC/GF-5}

The sun-synchronous orbit satellite of GF- 5 will be launching in China in 2018. Six sensors will be carried to observe the properties of atmospheric and surface. Thereinto, Directional Polarimetric Camera (DPC) can perform the multi-angle and polarized measurements. Its observation spectrum covers from visible to short-wave infrared band so as to detect the aerosols and clouds. DPC is designed by Anhui Institute of Optics and Fine Mechanics and the accuracy of polarized observation up to $2 \%$. It marks the maturing of the new generation of sensors in China.

\subsection{SMAC/GFDM-1}

The SMAC is a specialized sensor for the purpose of atmospheric correction of high resolution sensors. It has larger spectral range (490-2250nm) and equipped essential polarization bands at key bands for aerosol, cloud and surface monitoring. Noticeable, it has compact size and small weight for economical consideration. The SAMC on-board GFDM-1 satellite (a high spatial resolution satellite) has two pixels with each spatial resolution of about $7 \mathrm{~km}$. By simultaneously measuring atmospheric and surface parameters, it provides a near-real time correction of high spatial resolution images of the GFDM-1 satellite.

\subsection{POSP/HJ-2}

The POSP is an across-track scanning polarimeter with polarized channels from UV to MIR bands (410-2250nm) and without multi-angular capability. Its large scanning angle range $\left(65^{\circ}\right)$ provides wide swath coverage with middle spatial resolution (about $6 \mathrm{~km}$ ). The polarimetric measurements of earth-atmospheric system of Earth of POSP provide unique supplement to other sensors on-board Chinese HJ-2 satellite (HJ is short for Environment).

\subsection{PCF/GF-5(02)}

To further improve the accuracy of polarized observation, a suit of polarization crossfire (PCF) sensors has been put forward 
and will be onboard atmospheric and environmental satellite and expected to launch in 2019. The PCF has two polarized sensors named DPC and POSP. The DPC is the same of that onboard GF-5, while the POSP is a high arcuate polarization scanning radiometer with the cross-track scanning way. It can be achieved the calibration on satellite and ultraviolet polarization detection using PCF sensors which works better compared to independently using DPC.

\section{CONCLUSIONS}

Today, a rapid economic development in China has caused serious air pollution problems, especially the $\mathrm{PM}_{2.5}$. Monitoring of $\mathrm{PM}_{2.5}$ regional pollution based on remote sensing is extremely urgent. Polarized observation from satellite remote sensing provides a chance to solve the estimate of near surface $\mathrm{PM}_{2.5}$ mass concentration. Based on the polarized observation, we establish a suit of inversion algorithm so as to obtain the AOD and FMF which is the important parameters to estimate $\mathrm{PM}_{2.5}$. PBLH and $\mathrm{RH}$ are retrieved by maximum variance technique depended on active remote sensing and statistical synthetic regression method on infrared spectrum properties. Then, the $\mathrm{PM}_{2.5}$ distribution can be estimated using PMRS model.

A solution has been put forward based on full remote sensing observation. A case study shows that the accuracy of $\mathrm{PM}_{2.5}$ mass concentration near ground is improved and close to the model error. Although the case study has a high uncertainty, large number of independent verifications for AOD, FMF and $\mathrm{PM}_{2.5}$ indicate it's credible. For better support of estimating $\mathrm{PM}_{2.5}$, a new generation of polarimetric sensors will be launched in the near future, such as DPC and PCF. It will be greatly improved the monitoring of near surface $\mathrm{PM}_{2.5}$ mass concentrations.

\section{ACKNOWLEDGEMENTS}

This work was supported by the National Key R\&D Program of China (2016YFE0201400) and the National Natural Science Fund of China (41671367).

\section{REFERENCES}

Deuzé J.L., Bréon F.M., Devaux C., Goloub P., Herman M., Lafrance B., Maignan F., Marchand A., Nadal F., Perry G., et al. (2001). Remote sensing of aerosols over land surfaces from polder-adeos-1 polarized measurements. J. Geophys. Res., 106, 4913-4926.

Engel-Cox J. A., Holloman C. H., Coutant B. W. and Hoff R. M (2004). Qualitative and quantitative evaluation of MODIS satellite sensor data for regional and urban scale air quality. Atmospheric Environment, 38, 2495-2509.

Engel-Cox J. A., Young G. S. and Hoff R. M. (2005). Application of satellite remote-sensing data for source analysis of fine particulate matter transport events. Journal of the Air \& Waste Management Association, 55, 1389-1397.

Kaufman Y.J., Wald A.E., Remer L.A., Gao B.C. (1997). The MODIS $2.1 \mu \mathrm{m}$ channel-correlation with visible reflectance for use in remote sensing of aerosol. IEEE Trans. Geosci. Remote Sens., 35, 1286-1298.

Levy R.C., Remer L.A., Mattoo S., Vermote E.F., Kaufman Y.J. (2007). Second-generation operational algorithm: Retrieval of aerosol properties over land from inversion of moderate resolution imaging spectroradiometer spectral reflectance. J. Geophys. Res. Atmos., 112, 3710-3711.

Liu Y., Paciorek C. J. and Koutrakis P. (2009). Estimating regional spatial and temporal variability of $\mathrm{PM}_{2.5}$ concentrations using satellite data, meteorology, and land USE information. Environmental Health Perspectives, 117, 886-892.

Liu Z, Mortier A, Li Z, et al (2017). Improving Daytime Planetary Boundary Layer Height Determination from CALIOP: Validation Based on Ground-Based Lidar Station. Advances in Meteorology, 2017, (2017-6-4).

Tanré D., Bréon F.M., Deuzé J.L., Dubovik O., Ducos F., François P., Goloub P., Herman M., Lifermann A., Waquet F. (2011). Remote sensing of aerosols by using polarized, directional and spectral measurements within the a-train: The parasol mission. Atmos. Meas. Tech., 4, 1383-1395.

van Donkelaar A., Martin R. V., Brauer M., Kahn R., Levy R., Verduzco C., et al. (2010). Global estimates of ambient fine particulate matter concentrations from satellite-based aerosol optical depth: Development and application. Environmental Health Perspectives, 118, 847-855.

Wang J. and Christopher S. A. (2003). Intercomparison between satellite-derived aerosol optical thickness and $\mathrm{PM}_{2.5}$ mass: Implications for air quality studies. Geophysical Research Letters, 30. http://dx.doi.org/10.1029/2003gl018174.

Zhang W., Augustin M., Zhang Y. and Li Z. et al. (2014). Spatial and Temporal Variability of Aerosol Vertical Distribution Based on Lidar Observations: A Haze Case Study over Jinhua Basin, Advances in Meteorology, 349592, 1-8.

Zhang Y, Li Z., Qie L, Hou, W., Liu, Z., Zhang, Y., Xie Y., Chen X., Xu H. (2017). Retrieval of Aerosol Optical Depth Using the Empirical Orthogonal Functions (EOFs) Based on PARASOL Multi-Angle Intensity Data, Remote Sensing, 9(6): 578 .

Zhang, Y., Li Z., Qie, L., Zhang, Y., Liu, Z., Chen, X., Hou, W., Li, K., Li, D., and Xu, H. (2016). Retrieval of Aerosol FineMode Fraction from Intensity and Polarization Measurements by PARASOL over East Asia, Remote Sensing, 8, 417.

Zhang Y. and Li Z. (2015). Remote sensing of atmospheric fine particulate matter $\left(\mathrm{PM}_{2.5}\right)$ mass concentration near the ground from satellite observation, Remote Sensing of Environment, 160, $252-262$. 